\title{
Clinical study on the comparison of gold and zirconia wear in an implant-supported fixed prosthesis
}

\author{
Jee-Hwan Kim†, Seung-Won $\mathrm{Yang}^{1}{ }^{\dagger}$, NamSik Oh ${ }^{3 *}$ \\ 'Department of Prosthodontics, Oral Science Research Center, College of Dentistry, Yonsei University, Seoul, Republic of Korea \\ 2Department of Prosthodontics, College of Dentistry, Yonsei University, Seoul, Republic of Korea \\ ${ }^{3}$ Division in Prosthodontics, Department of Dentistry, School of Medicine, Inha University, Incheon, Republic of Korea
}

Purpose: The purpose of this study was to compare and analyze the wear of a prosthesis for 6 months after restoration with implant-supported fixed dental prosthesis made of either zirconia or gold. Materials and Methods: This study was conducted on patients requiring implant-supported fixed dental prostheses on first or second molar from January, 2015 to January, 2016. A total of 47 prostheses and antagonists were examined. Occlusal surface was recorded by impression of each prosthesis and antagonist 1 week and 6 months after prosthesis delivery. The digital files were created by impression scan. Occlusal shapes of 1 week and 6 months were compared and wear of prostheses and antagonists was analyzed. The Mann-Whitney test was used to analyzed the result data underwent normality test using SPSS (Version 23.0, IBM Corporation) Results: Mann-Whitney test revealed that there was no statistically significant difference in the median amount of mean vertical wear for 6 months in zirconia $(50.84 \mu \mathrm{m})$ and gold $(42.84$ $\mu \mathrm{m})$ prostheses $(P>0.05)$. When the opposing teeth were natural, the median amount of mean vertical wear of zirconia and gold prostheses was $47.72 \mu \mathrm{m}$ and $41.97 \mu \mathrm{m}$, respectively, and the median amount of mean vertical wear of enamel was $47.26 \mu \mathrm{m}$ and $44.59 \mu \mathrm{m}$, respectively. Statistical analysis showed no significant difference $(P>0.05)$. Conclusion: Despite the short study period and the small number of experimental groups, zirconia and gold showed no significant difference in wear during the first 6 months. Opposing natural enamel also showed no significant difference in the wear. (J Dent Rehabil Appl Sci 2017;33(4):252-9)

Key words: implant prosthesis; wear; zirconia; occlusal wear; prosthetic material

\begin{abstract}
서론
고정성보철 수복 치료에는 금전장관, 금속도재관, 전 부도재관 등 다양한 재료가 사용된다. 임상적으로 오랜 기간 사용된 금전장관은 생체친화적이며 변연 적합성이 좋고, 대합치의 마모를 적게 유발한다는 장점이 있다. 하 지만, 금전장관은 색상으로 인해 심미성이 떨어진다는 단점이 존재한다. 이에 금속도재관, 전부도재관 등의 심 미적인 재료의 개발이 진행되었다.
\end{abstract}

\footnotetext{
*Correspondence to: NamSik Oh

Professor, Devision in Prosthodontics, Department of Dentistry, School of

Medicine, Inha University, 7-206, \#3 Shinhung-dong, Jung-gu, Incheon, 22332,

Republic of Korea

Tel: +82-32-890-2470, Fax: +82-32-890-2475, E-mail: onsdo@inha.ac.kr

Received: June 24, 2017/Last Revision: September 6, 2017/Accepted: September

7, 2017

† These authors equally contributed to this work as first authors.
}

252
과거의 전부도재관은 금속도재관에 비해 낮은 인장 강 도 및 낮은 경도를 가지며 취성 및 파절에 대한 저항성이 낮아, 전부도재관의 사용이 제한되었다. 그러나, 현재 기 술의 발전과 더불어 전부도재관의 성질이 개선되었으며, 좋은 생체적합성과 높은 심미성으로 인해 최근 들어서 널리 사용되고 있다.

최근에 소개된 재료인 지르코니아는 zirconium의 crystalline dioxide로, partially stabilized zirconia이다. 지 르코니아는 화학적으로 안정한 구조를 지니며, 부피안

Copyright@ 2017 The Korean Academy of Stomatognathic Function and Occlusion. (c) It is identical to Creative Commons Non-Commercial License. 
정성이 있고, 기계적 성질이 뛰어나다. 특히, transformation toughening mechanism을 통해 균열의 전파를 억제 하는 성질이 있다. ${ }^{1}$ 이 기전은 상전이 현상을 통해 일어나 며, 기존의 도재에 비해 높은 파절강도와 경도를 지니게 한다. 그 결과 임상적 사용이 증가하고 있다. ${ }^{1,2}$

Monolithic zirconia에서 관심있는 특성 중 하나는 마 모적 측면이며, 특히 자연치의 법랑질과 대합되는 경우이 다. 많은 실험 연구에서 다양한 시뮬레이션 기계를 통해 마모에 대한 측정을 시행하였다. 이러한 연구들의 결과 로 지르코니아는 다른 치과용 세라믹에 비해 더 높은 마 모저항성을 가지며, 여러 치과용 세라믹과 비교해 대합치 에 비슷한 마모를 야기하거나, 더 적은 마모를 야기함이 밝혀졌다. $3-5$

치아의 마모는 복잡하다. 생물학적, 기계적, 화학적 요 소 등이 작용하는 다요인 현상이기 때문이다. 마모 현상 은 관절 병리, 교합, 근긴장도, 윤활작용, 개개인의 식습 관, 그리고 사용된 수복 재료의 종류에 따라 다양하게 나 타난다. ${ }^{6,7}$ 다양한 치과 수복 재료는 그 특성이 다르며, 대 합되는 자연치의 마모 또한 다양하게 나타난다. 이상적 으로, 수복 재료의 마모도는 대합되는 자연치와 비슷해 야 한다. ${ }^{8}$ 마모는 구강악안면계의 건강에 영향을 미치며, 수직 고경의 감소, 심미의 악화, 치아 민감성의 증가, 그 리고 저작기능 감소를 야기한다. 그러므로, 치과 수복 재료의 선택에 있어 대합되는 치아와 수복 재료 사이에 서 발생하는 마모에 대한 고려가 필요하다.

초기의 마모에 관한 연구는 대개 금과 도재의 마모 비 교를 시행하였다. Corrine 등은 금이 도재에 비해 더 적 은 재료의 마모 및 더 적은 대합치의 마모를 보인다 하였 다. ${ }^{9}$ Al-Hiyasat 등의 연구도 비슷한 결과를 보였다. ${ }^{10}$ 두 연구에서 도재에 비해 금이, 마모적 측면에 있어 도재보 다 좋은 재료임이 밝혀졌지만, 지르코니아의 마모에 대 한 연구는 이루어지지 않았다. 이후 지르코니아의 발전 과 함께 지르코니아와 도재의 마모 비교에 관한 연구가 시행되었다. Sridhar 등은 일반적인 도재에 비해 지르코 니아의 마모가 더 적음을 확인하였다. ${ }^{11}$

하지만, 실험연구는 그 한계점이 있다. 그 예로 한두개 의 제한된 저작 시뮬레이션 환경 하에서 마모 양상을 평 가한다는 것이다. 모든 마모 실험 방법은 임상적 연관성 이 결여된다는 단점이 있다. 그러므로 지르코니아 보철물 에 대한 임상적인 마모 평가가 필요하다. Mundhe 등은 1 년간의 마모를 확인하는 임상연구에서 지르코니아가 도 재에 비해 더 적은 대합치의 마모를 야기한다고 하였다. ${ }^{12}$
그러나, 현재까지 이루어진 임상연구의 수가 많지 않 다. 더욱이, 지르코니아와 금의 비교에 관한 임상 연구는 이루어지지 않았다. 또한, 대부분의 임상적 마모 연구는 자연치에 보철 수복을 한 경우에 한해 시행되었으며, 임 플란트 지지 고정성 보철물로 수복한 경우는 없었다. 여 러 선행 연구를 통해 도재와 비교했을 때, 금전장관 뿐만 아니라, 지르코니아 전장관 또한 마모적 측면에서 좋은 결과를 보임을 알 수 있다. 그러나, 추가적인 금과 지르코 니아 두 재료의 비교 연구가 요구된다. 더욱이, 현재 부분 무치악에 대해 임플란트 치료가 활발히 이루어지며, 임 플란트 지지 고정성 보철물로 금전장관, 지르코니아 전 장관 모두 수복 재료로 사용되고 있기 때문에, 임플란트 지지 고정성 보철물에서의 두 재료에 대한 임상적 마모 연구가 필요하다.

본 연구는 지르코니아 전장관과 금전장관 및 그에 대 합되는 치아의 마모를 비교, 평가하기 위해 디자인 되었 다. 본 연구의 목적은 임플란트 지지 고정성 보철물에서 지르코니아 전장관 또는 금전장관으로 수복한 후 보철 물과 대합치의 6 개월 간의 수직거리 차를 비교, 분석하는 것이다.

\section{연구 재료 및 방법}

\section{1. 연구 대상}

2015년 1월부터 2016년 1월까지 연세대학교 치과대 학병원 보철과에 내원한 환자를 대상으로, 본 시험에 참 여할 것을 자발적으로 동의한 환자, 임플란트 지지 고정 성 보철물로 대구치 부분무치악 부위의 수복을 요하는 환자, 만 18세 이상인 환자, 턱관절 및 기타 교합장애가 없는 환자를 선별하였다. 그 중, 대합치의 심한 우식 또는 파절이 있는 경우, 대합치의 수복을 요하는 경우, 대합치 의 동요도가 존재하는 경우, 기타 임상의에 의해 부적합 하다고 판단되는 환자는 제외하였다. 본 연구는 연세대 학교 치과대학의 임상시험심사위원회(IRB, Institutional Review Board)의 심의 및 승인(승인번호: 2-2017-0042) 을 받았다.

\section{2. 연구 방법}

1) 보철물 제작 및 장착

임플란트와 골 사이의 안정적인 골 유착이 확인된 후, 
통상적인 방법에 따라 임플란트 고정성 보철물의 제작을 진행하였다. 보철물은 지르코니아 전장관 또는 금전장 관으로 제작하였으며, screw cement retained prosthesis (SCRP) 형태로 제작하였다. 제작된 보철물은 숙련된 1명 의 치과의사가 구강 내에 시적하였다. 필요에 따라 인접 면, 교합면에 대한 조정을 시행한 후 premier implant cement (Premier ${ }^{\circledR}$ Dental Products Company, Plymouth Meeting, USA)를 이용하여 접착하였으며, screw access hole은 레진을 이용하여 수복하였다.

\section{2) 교합면 형태 기록시기 및 방법}

보철물 장착 1 주일 후, 보철물의 교합면 상태를 인기 하였다. 금전장관으로 수복한 경우 폴리이써(Impregum Penta, 3M ESPE Dental AG, Seefeld, Germany)를 이용 하여 폐구 인상채득을 시행하였다. 인상채득 후 탁상용 스캐너(Identica blue, Medit ${ }^{\circledR}$, Seoul, Korea)로 인상체 스 캔하였다. 한편, 지르코니아로 수복한 경우 금전장관의 교합면 상태를 인기한 방법과 동일하게 지르코니아 전 장관의 교합면 상태를 인기하였다. 또는, $\operatorname{trios}^{\circledR}$ (3shape Dental System, Copenhagen, Denmark) 구강 스캐너를 이용하여 구강 내에서 직접 교합면 스캔을 시행하였다. 보철물 장착 6 개월 후, 보철물 장착 1 주일 후와 동일한 방법으로 보철물의 상태를 인기하여 1 주일 및 6 개월의 stereolithography (STL) 파일을 추출하였다.

3) 교합면의 비교

Rapidform 2006 소프트웨어(INUS Technology and Rapidform Inc, Seoul, Korea)를 이용하여 보철물 장착 1 주일 후 및 6개월 후의 STL 파일을 중첩하였으며, 이후 보철물 및 대합치의 교합면을 추출하였다(Fig. 1). 대상 보철물은 SCRP 형태로 수복 및 레진을 이용하여 screw access hole을 수복하였기에, 보철물의 마모 확인을 위해 레진 부위는 제외하였다. 그 후, Rapidform 2006 프로그 램을 이용하여 6개월 간의 마모 분석을 위한 수직거리 차 를 계산하였다(Fig. 2).

\section{4) 통계분석}

데이터의 통계 분석은 IBM SPSS 23.0 소프트웨어 (IBM Corporation, Armonk, USA)를 이용하여 진행하 였다. 기술통계를 위한 분석을 시행하였다. 지르코니아 전장관 혹은 금전장관, 보철물의 종류에 따른 마모와, 대합치가 자연치인 경우 보철물의 마모 및 대합치의 마 모를 나타내는 수직거리 차의 지표들은 정규분포를 따 르지 않았다. 이에, 그룹간 유의성 확인을 위해 MannWhitney 분석을 시행하였다.
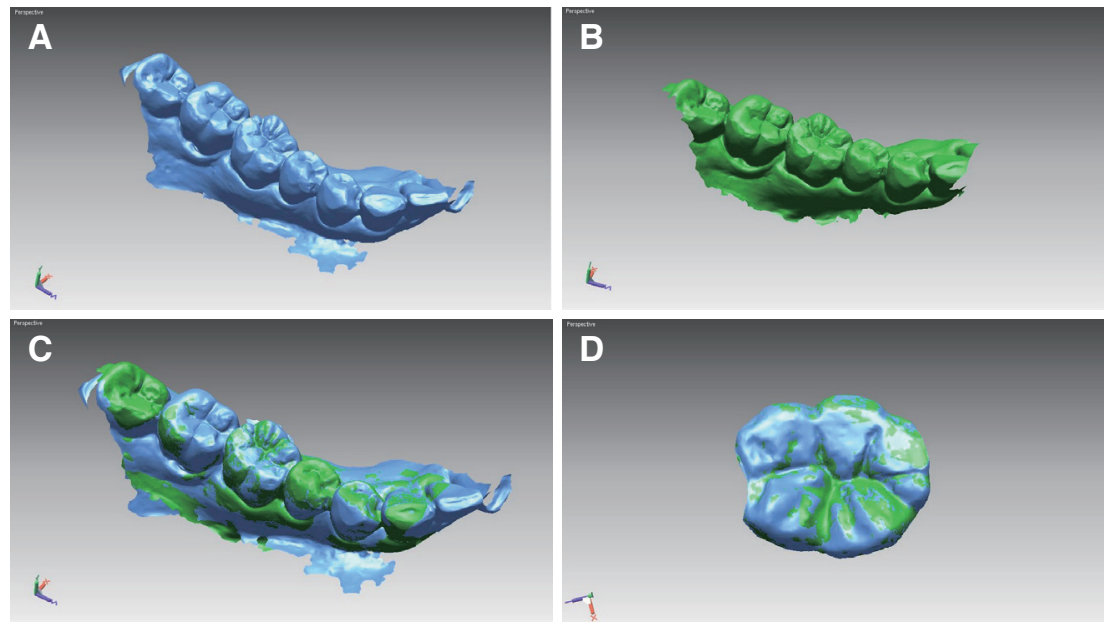

Fig. 1. Deviation analysis procedure. (A) Scanned 3-dimensional images of target tooth at baseline (1 week), (B) Scanned 3-dimensional images of target tooth after 6 months, (C) Superimposed image of target tooth from 1 week and 6 months by Rapidform algorithm, (D) Extraction of target tooth.

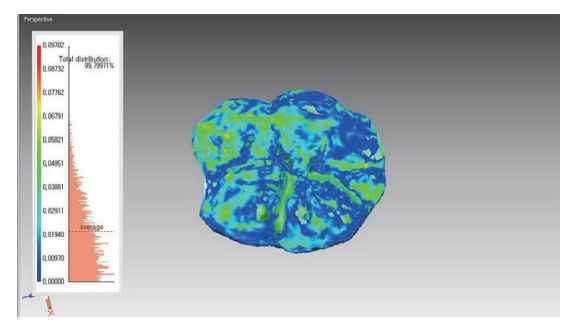

Fig. 2. Deviation analysis, occlusal view of result shows maximum and mean vertical difference. 


\section{결과}

본 연구에서 총 35 명의 환자, 47 개의 보철물 및 대합 치에 대해 조사하였다. 보철물에 대하여 금전장관 7개(7 명), 지르코니아 전장관 40개(28명)가 포함되었다. 지르 코니아 전장관 보철물의 대합치로 자연치 24 개, 금전장 관 6 개, 지르코니아 전장관 7 개, 금속도재관 1개(도재 교 합), 금속도재관 2개(금속 교합)로 조사되었다. 금전장관 보철물의 대합치는 자연치 5 개, 금전장관 2 개로 조사되 었다(Table 1).

보철물 장착 후 초기 6개월간의 수직거리 차에 대해 평가하였다. 지르코니아의 최대 수직거리 차는 중앙값 $225.91 \mu \mathrm{m}$ 이며, 평균 수직거리 차는 중앙값 $50.84 \mu \mathrm{m}$

Table 1. Implant-supported fixed dental prostheses and antagonists

\begin{tabular}{lcc}
\hline & $\begin{array}{c}\text { Implant-supported fixed } \\
\text { dental prostheses }\end{array}$ \\
Antagonists & Zirconia crown & Gold crown \\
\hline Natural tooth (n) & 24 & 5 \\
Gold crown (n) & 6 & 2 \\
Zirconia crown (n) & 7 & \\
PFG crown, porcelain (n) & 1 & \\
PFG crown, gold (n) & 2 & 7 \\
Total (n) & 40 & \\
\hline
\end{tabular}

로 나타났다. 금전장관의 최대 수직거리 차는 중앙값 $211.85 \mu \mathrm{m}$ 이며, 평균 수직거리 차는 중앙값 $42.84 \mu \mathrm{m}$ 로 나타났다(Table 2). 두 보철물의 6개월간 수직거리 차의 차이를 비교하기 위해 Mann-Whitney 분석을 시행한 결 과 보철물의 최대 수직거리 차, 평균 수직거리 차에서 유 의한 차이가 없었다 $(P>0.05)$ 는 점을 확인하였다(Table 3).

대합치를 자연치로 제한한 경우에 한하여 동일한 방법 으로 조사를 시행하였다. 이 때, 보철물과 대합치의 수직 거리 차를 함께 조사하였다. 보철물이 지르코니아인 경 우 지르코니아의 최대 수직거리 차는 중앙값 $226.56 \mu \mathrm{m}$ 이며, 평균 수직거리 차는 중앙값 $47.72 \mu \mathrm{m}$ 로 나타났다. 지르코니아에 대합되는 자연치 법랑질의 최대 수직거리 차는 중앙값 $243.56 \mu \mathrm{m}$ 이며, 평균 수직거리 차는 중앙 값 $47.26 \mu \mathrm{m}$ 로 나타났다. 보철물이 금전장관인 경우 금 전장관의 최대 수직거리 차는 중앙값 $211.85 \mu \mathrm{m}$ 이며, 평 균 수직거리 차는 중앙값 $41.97 \mu \mathrm{m}$ 로 나타났다. 금전장 관에 대합되는 자연치 법랑질의 최대 수직거리 차는 중 앙값 $258.27 \mu \mathrm{m}$ 이며, 평균 수직거리 차는 중앙값 44.59 $\mu \mathrm{m}$ 로 나타났다(Table 4). 두 보철물의 6개월간 수직거리 차의 비교, 그리고 대합치의 수직거리 차의 비교에 있어 Mann-Whitney 분석을 시행한 결과 보철물의 최대 수직 거리 차, 평균 수직거리 차와, 대합치의 최대 수직거리 차, 평균 수직거리 차에서 유의한 차이가 없었다 $(P>0.05)$ (Table 5).

Table 2. Median, first quartile, third quartile, interquartile range of maximum and mean vertical wear of prosthesis including all cases

\begin{tabular}{lrrrr}
\hline & Median & First quartile & Third quartile & Interquartile range \\
\hline Zirconia crown & & & & \\
Maximum vertical wear $(\mu \mathrm{m})$ & 225.91 & 203.59 & 243.25 & 39.66 \\
Mean vertical wear $(\mu \mathrm{m})$ & 50.84 & 35.88 & 60.64 & 24.76 \\
Gold crown & & & & \\
Maximum vertical wear $(\mu \mathrm{m})$ & 211.85 & 166.73 & 248.48 & 81.75 \\
Mean vertical wear $(\mu \mathrm{m})$ & 42.84 & 36.96 & 61.91 & 24.95 \\
\hline
\end{tabular}

Table 3. Comparison of maximum and mean vertical wear of prosthesis including all cases (Mann-Whitney test)

\begin{tabular}{lc}
\hline \multicolumn{1}{c}{ Groups compared } & $P$ \\
\hline Maximum vertical wear of zirconia crown vs maximum vertical wear of gold crown & 0.676 \\
Mean vertical wear of zirconia crown vs mean vertical wear of gold crown & 0.905 \\
\hline
\end{tabular}


Table 4. Median, first quartile, third quartile, interquartile range of maximum and mean vertical wear of prosthesis and antagonist when opposed to natural tooth

\begin{tabular}{|c|c|c|c|c|}
\hline & Median & First quartile & Third quartile & Interquartile range \\
\hline \multicolumn{5}{|l|}{ Zirconia crown } \\
\hline Maximum vertical wear $(\mu \mathrm{m})$ & 226.56 & 203.84 & 242.70 & 38.86 \\
\hline Mean vertical wear $(\mu \mathrm{m})$ & 47.72 & 35.59 & 56.45 & 20.86 \\
\hline \multicolumn{5}{|l|}{ Zirconia crown antagonist } \\
\hline Maximum vertical wear $(\mu \mathrm{m})$ & 243.56 & 221.03 & 257.95 & 36.92 \\
\hline Mean vertical wear $(\mu \mathrm{m})$ & 47.26 & 40.91 & 59.56 & 18.65 \\
\hline \multicolumn{5}{|l|}{ Gold crown } \\
\hline Maximum vertical wear $(\mu \mathrm{m})$ & 211.85 & 133.21 & 244.10 & 110.89 \\
\hline Mean vertical wear $(\mu \mathrm{m})$ & 41.97 & 31.94 & 42.84 & 10.90 \\
\hline \multicolumn{5}{|l|}{ Gold crown antagonist } \\
\hline Maximum vertical wear $(\mu \mathrm{m})$ & 258.27 & 245.27 & 263.28 & 18.01 \\
\hline Mean vertical wear $(\mu \mathrm{m})$ & 44.59 & 43.14 & 62.96 & 19.82 \\
\hline
\end{tabular}

Table 5. Comparison of maximum and mean vertical wear of prosthesis and antagonist when opposed to natural tooth (Mann-Whitney test)

\begin{tabular}{lcc}
\hline Groups compared & $P$ \\
\hline Maximum vertical wear of zirconia crown vs maximum vertical wear of gold crown & 0.603 & 0.419 \\
Mean vertical wear of zirconia crown vs mean vertical wear of gold crown & 0.356 & 0.954 \\
Maximum vertical wear of zirconia crown antagonist vs maximum vertical wear of gold crown antagonist & \\
Mean vertical wear of zirconia crown antagonist vs mean vertical wear of gold crown antagonist & \\
\hline
\end{tabular}

\section{고찰}

치아와 수복재료의 구성과 물리적 성질의 차이가 존재 하기에 시간이 지남에 따라 서로 다른 마모가 발생한다. 이러한 마모양상의 차이는 수복재료나 대합치의 과도한 마모를 야기할 수 있으며, 결과적으로 교합불안정, 치아 과민증, 또는 심미의 저하를 야기할 수 있다. 그러므로, 수복재료 및 대합되는 치아의 마모에 대한 연구가 중요 하다.

최근 널리 사용되는 지르코니아 보철물에서, 도재 비니 어를 이용한 지르코니아는 도재의 파절 혹은 계면의 분 리와 같은 주요한 기계적 부작용이 존재한다. 비록 도재 비니어 기술이 발달했다 해도 성공적인 비니어를 보장하 지 못한다. 그러므로, 비니어를 제거하는 방법으로 응집 성 파절 또는 접착성 파절을 방지할 수 있다. 그러나, 이 런 기계적 문제점 외에도 수복재료와 대합치의 마모 문 제는 재료 선택을 제한하는 측면이 있다. 많은 실험 연구
에서 다양한 치과 재료의 마모에 관한 분석이 이루어졌 지만, 임상 실험에서의 법랑질 마모에 대한 연구는 적게 보고되었다. 비록 많은 실험 연구들은 그 환경을 제한하 고, 치아 경조직과 생체 재료의 마모에 영향을 미칠 수 있 는 여러 환경을 제한하였지만, 실험 연구와 임상적 상황 에는 차이점이 존재한다. 임상적 환경은 어떠한 방법으 로도 동일하게 재현할 수 없기에, 마모 평가에 있어 임상 연구가 요구된다.

이 연구는 지르코니아와 금전장관으로 임플란트 지지 고정성 보철물을 수복한 후, 보철물과 대합치의 6 개월간 의 마모에 대해 조사하였다. 대합치의 종류를 제한하지 않았을 때, 지르코니아 전장관과 금전장관 보철물의 6 개 월간 마모의 차이는 발견되지 않았다. 또한, 대합치가 자 연치의 법랑질인 경우, 지르코니아 전장관과 금전장관 보철물의 마모 뿐만 아니라, 대합되는 법랑질의 마모 또 한 유의한 차이가 없었다.

마모에 관한 연구는 활발히 이루어졌지만, 대개 실험 
연구에 국한되어 있다. Corrine 등은 타액의 환경에서 법 랑질에 대합되는 다양한 재료의 마모를 분석하는 실험 연구를 진행하였다. 그 결과 금의 평균 마모는 $0.32 \mu \mathrm{m}$, 전부도재관의 평균 마모는 은 $4.3 \mu \mathrm{m}$ 였으며, 금에 대합 되는 법랑질은 평균 $9 \mu \mathrm{m}$, 전부도재관에 대합되는 법랑 질은 평균 $230 \mu \mathrm{m}$ 의 마모가 발생하였다. 이를 통해 도재 에 비해 금이 재료 및 그 대합치의 적은 마모를 유발한다 보고하였다. 또한, Al-Hiyasat 등은 금과 도재의 법랑질 에 대한 마모에 관한 실험적 연구를 진행하였다. 그 연구 에서, 금은 $16.28 \mu \mathrm{m}$, 금에 대합되는 법랑질은 $90 \mu \mathrm{m}$ 의 마모를 보인 반면, 도재는 $41.88 \mu \mathrm{m}$, 도재에 대합되는 법 랑질은 $540 \mu \mathrm{m}$ 의 마모를 보였다. ${ }^{10}$ 그밖에도 다양한 연 구에서 금 재료가 도재에 비해 더 적은 마모를 보임이 보 고되었다. 한편, Kwon 등은 지르코니아와 대합되는 조 건에서 법랑질, 금, 그리고 지르코니아의 마모를 비교하 였다. 이 실험에서 금과 지르코니아는 $0.01 \mathrm{~mm}^{3}$ 정도로 비슷한 마모를 보이는 것으로 밝혀졌다. ${ }^{13}$ 그러나 법랑질 과 대합되는 조건에서의 금과 지르코니아의 마모에 대한 조사는 이루어지지 않았다. 한편, Mundhe 등은 1년간의 마모를 조사하는 임상 연구에서 지르코니아에 대합되는 법랑질은 $127 \mu \mathrm{m}$, 도재에 대합되는 법랑질은 $179 \mu \mathrm{m}$ 의 마모를 보임을 확인하였다. ${ }^{12}$

기존의 연구들은 각기 다른 조건 하에서 실험이 시행되 었으며, 보철물 및 대합치의 마모 측정법 또한 상이하기 에, 본 연구의 결과와 직접적으로 비교하는 것은 어렵다. 또한, 마모에 대한 임상연구는 진행된 바가 적으며, 더욱 이 임플란트 지지 고정성 보철물에서 금과 지르코니아의 마모에 대한 연구는 이루어진 바가 없기에 선행연구와의 비교가 불가하다.

본 연구에서는 보철물과 대합치의 6 개월간 마모가 평 균적으로 $40-50 \mu \mathrm{m}$ 로 측정되었다. 보통 자연치 법랑질 이 1년간 $20-30 \mu \mathrm{m}$ 정도의 마모가 발생한다는 것을 기 준으로 보면, 본 실험에서는 더 많은 마모가 발생한 것을 확인할 수 있다. 그러나, Mundhe의 임상연구와 비교했 을 때, 지르코니아에 대합되는 법랑질은 마모가 더 적게 발생하였음을 알 수 있다. 여러 선행 연구들을 통해 금은 오랫동안 사용된 좋은 수복재료임을 확인할 수 있으며, 본 연구에서 지르코니아 또한 마모적 측면에서 금과 비 슷한 양상을 보임이 확인되었다. 그러나, 본 연구에서는 지르코니아 전장관과 금전장관의 디지털 파일 형성 과정 이 상이하였으며, 임플란트 지지 고정성 보철물에 대한 조사를 시행하였고, 특히 금 재료에서 시편의 수가 적은
한계가 있기에 추가적인 연구가 필요할 것이다.

\section{결론}

본 연구에서는 임플란트 고정성 보철물로 수복한 지르 코니아 전장관과 금전장관 및 그 대합치의 6 개월간 마모 에 대해 분석하였다. 대합치에 제한이 없는 경우, 지르코 니아 전장관과 금전장관 보철물 사이의 마모 차이는 없 었으며, 대합치가 자연치인 경우 보철물과 대합치간 마 모 차이 또한 존재하지 않는 것으로 확인되었다. 이 실험 의 한계 내에서, 지르코니아 전장관은 금전장관과 같은 마모성을 지니며, 좋은 보철수복 재료로 사용될 수 있다 는 결론을 내렸다.

\section{Acknowledgements}

이 논문은 2014년도 대한턱관절교합학회 연구과제 연 구비(KASFO-2014-03)에 의하여 연구되었음.

\section{ORCID}

Jee-Hwan Kim https://orcid.org/0000-0002-0872-4906 Seung-Won Yang https://orcid.org/0000-0002-7907-6467

NamSik Oh https://orcid.org/0000-0002-0155-7746

\section{References}

1. Piconi C, Maccauro G. Zirconia as a ceramic biomaterial. Biomaterials 1999;20:1-25.

2. Guazzato M, Albakry M, Ringer SP, Swain MV. Strength, fracture toughness and microstructure of a selection of all-ceramic materials. Part II. Zirconia-based dental ceramics. Dent Mater 2004;20:44956.

3. Beuer F, Stimmelmayr M, Gueth JF, Edelhoff D, Naumann M. In vitro performance of full-contour zirconia single crowns. Dent Mater 2012;28:449-56.

4. Kim MJ, Oh SH, Kim JH, Ju SW, Seo DG, Jun $\mathrm{SH}$, Ahn JS, Ryu JJ. Wear evaluation of the human enamel opposing different Y-TZP dental ceramics and other porcelains. J Dent 2012;40:979-88.

5. Mitov G, Heintze SD, Walz S, Woll K, Muecklich F, Pospiech P. Wear behavior of dental Y-TZP ce- 
ramic against natural enamel after different finishing procedures. Dent Mater 2012;28:909-18.

6. Heintze SD, Cavalleri A, Forjanic M, Zellweger G, Rousson V. Wear of ceramic and antagonist-a systematic evaluation of influencing factors in vitro. Dent Mater 2008;24:433-49.

7. Mahalick JA, Knap FJ, Weiter EJ. Occlusal wear in prosthodontics. J Am Dent Assoc 1971;82:154-9.

8. Sulong MZ, Aziz RA. Wear of materials used in dentistry: a review of the literature. J Prosthet Dent 1990;63:342-9.

9. Hacker CH, Wagner WC, Razzoog ME. An in vitro investigation of the wear of enamel on porcelain and gold in saliva. J Prosthet Dent 1996;75:14-7.

10. al-Hiyasat AS, Saunders WP, Sharkey SW, Smith
GM, Gilmour WH. Investigation of human enamel wear against four dental ceramics and gold. J Dent 1998;26:487-95.

11. Janyavula S, Lawson N, Cakir D, Beck P, Ramp LC, Burgess JO. The wear of polished and glazed zirconia against enamel. J Prosthet Dent 2013;109:22-9.

12. Mundhe K, Jain V, Pruthi G, Shah N. Clinical study to evaluate the wear of natural enamel antagonist to zirconia and metal ceramic crowns. J Prosthet Dent 2015;114:358-63.

13. Kwon MS, Oh SY, Cho SA. Two-body wear comparison of zirconia crown, gold crown, and enamel against zirconia. J Mech Behav Biomed Mater 2015; 47:21-8. 


\section{임플란트 지지 고정성 보철물에서 금과 지르코니아의 마모 비교에 대한 임상 연구}

\section{김지환 ${ }^{1 \dagger}$, 양승원 ${ }^{2 \dagger}$, 오남식 ${ }^{3 *}$}

${ }^{1}$ 연세대학교 치과대학 보철과학교실

${ }^{2}$ 연세대학교 치과대학 보철과학교실

${ }^{3}$ 인하대학교 의과대학 치과학교실

목적: 본 연구의 목적은 지르코니아 전장관과 금전장관으로 수복된 임플란트 지지 고정성 보철물의 장착 후 초기 6개월 간의 마모를 비교 분석하는 것이다.

연구 재료 및 방법: 2015년 1월부터 2016년 1월까지, 대구치 부위에 임플란트 지지 고정성 보철 수복을 요하는 환자를 대 상으로 하였다. 총 47 개에 대하여 임플란트 지지 고정성 보철물과 대합치에 대해 조사를 시행하였으며, 보철물 장착 1 주 및 6개월 후 보철물 및 대합치를 인상채득 하여 교합면의 형태를 인기 하였다. 인상체를 스캔하여 보철물 및 대합치의 교 합면 형태를 비교하여 마모 분석을 시행하였다. SPSS (Version 23.0; SPSS, IBM Corporation, Armonk, USA) 프로그램 을 이용하여 정규성 분석 후 Mann-Whitney 분석을 시행하였다.

결과: 임플란트 지지 고정성 보철물에서 지르코니아 전장관과 금전장관 보철물의 6 개월간 평균 수직거리 차의 중앙값은 각각 $50.84 \mu \mathrm{m}, 42.84 \mu \mathrm{m}$ 로 통계적 유의차가 없었다 $(P>0.05)$. 대합치가 자연치인 경우, 지르코니아 전장관 및 금전장 관 보철물의 6개월간 평균 수직거리 차의 중앙값은 각각 $47.72 \mu \mathrm{m}, 41.97 \mu \mathrm{m}$ 였으며, 대합치 법랑질의 평균 수직거리 차 의 중앙값은 각각 $47.26 \mu \mathrm{m}, 44.59 \mu \mathrm{m}$ 이었고, 통계적 유의차는 없었다 $(P>0.05)$.

결론: 조사 기간이 짧았고, 실험군의 개수가 적었다는 단점이 있지만, 임플란트 지지 고정성 보철물 장착 후 초기 6개월 간의 마모 비교에서 지르코니아 전장관과 금전장관은 유의한 차이가 없었고, 대합되는 자연치 법랑질의 마모도 유의한 차이는 없었다.

(구강회복응용과학지 2017;33(4):252-9)

주요어: 임플란트 보철; 마모; 지르코니아; 교합면의 마모; 보철재료

*교신저자: 오남식

(22332)인천광역시 중구 신흥동3가 7-206 인하대학교 의과대학 치과학교실

Tel: 032-890-2470 | Fax: 032-890-2475 | E-mail: onsdo@inha.ac. kr 접수일: 2017년 6월 24일 | 수정일: 2017년 9월 6일 | 채택일: 2017년 9월 7일

$\dagger$ 본 저자는 제1저자로서 동등하게 기여함. 